\title{
Clinico-pathological study of ovarian tumors at tertiary care hospital, Udaipur
}

\section{Runjhun Jain*, Pooja Patel, Sharda Goyal}

Department of Obstetrics and Gynaecology GMCH, Udaipur, Rajasthan, India

Received: 17 November 2020

Revised: 20 December 2020

Accepted: 29 December 2020

\author{
*Correspondence: \\ Dr. Runjhun Jain, \\ E-mail: bsntshrm83@gmail.com
}

Copyright: (C) the author(s), publisher and licensee Medip Academy. This is an open-access article distributed under the terms of the Creative Commons Attribution Non-Commercial License, which permits unrestricted non-commercial use, distribution, and reproduction in any medium, provided the original work is properly cited.

\begin{abstract}
Background: Diagnosis of malignancy in ovarian tumour is always questionable clinically as well as by investigation. Ovarian tumour arise in any age group and any type of body tissue present in tumour like epithelial tissues, germ cells, embryonic cells due to varied histology of ovary and metastatic non ovarian tumours. Aim and objective of the study was to study the correlation ovarian masses regarding their clinical presentation investigation and histo-pathological report.

Methods: All the women who presented with lump and/or pain or menstrual problem attending Gynecology, Surgery and oncology OPD of GMCH, Udaipur. Our study design is prospective hospital based study. The statistical analysis was performed using IBM statistical for social sciences (SPSS).

Results: In our study, $85.43 \%$ were benign tumour and $12.67 \%$ were malignant tumour. Among this, $70.87 \%$ were cystic, $14.56 \%$ were solid and $14.56 \%$ were mixed tumours. Mostly they were epithelial tumours (85.43\%). Main surgery was total hysterectomy with bilateral salpingoopherectomy. In malignant tumours $61.53 \%$ also had Chemotherapy and $0.97 \%$ had debulking.

Conclusions: There is strong correlation of ultrasonography finding with histopathology report. Though clinically it was $55 \%$ only. Specificity of the Ultrasonography was $73.33 \%$ but sensitivity was $100 \%$. Positive predictive value was $95.65 \%$ and negative predictive value was $100 \%$.
\end{abstract}

Keywords: Benign, Malignant tumors, Ovary, Ultrasonography

\section{INTRODUCTION}

Ovary is a main organ of reproduction but its tumour is always notorious. Ovarian tumours are complex tumours which are diagnosed very late due to asymptomatic initially. Diagnosis of malignancy in ovarian tumour is always questionable clinically as well as by investigation. Ovarian tumour arise in any age group and any type of body tissue present in tumour like epithelial tissues, germ cells, embryonic cells due to varied histology of ovary and metastatic non ovarian tumours. Ovarian malignancies are diagnosed late, because of non-specific symptoms initially like discomfort, bloating back pain or urinary symptoms or mainly asymptomatic. ${ }^{1}$ Symptoms appear in later stage of malignancy. Most ovarian tumors cannot be distinguished confidently on the basis of their clinical or gross characteristics alone. ${ }^{2}$ Dilemma of differentiating a benign from a malignant tumour always exists by clinical examination. Imaging by USG though helps to locate origin size, consistency of tumour but diagnosis of malignancy in ovarian tumour by USG, CA125, MRI and other method is difficult. Our tertiary center has all facilities for diagnosing and treating ovarian tumours. Hence, this study has been to diagnosis to know incidence of ovarian tumours, mode of presentation and exact diagnosis by corelating various 
diagnostic tools. In this study we correlated ovarian masses regarding their clinical presentation investigation and histo-pathological report.

Fonseea et al studied 30 patients with ovarian masses and observed that $50 \%$ were functional cysts, $46.6 \%$ were benign ovarian masses and $3.3 \%$ were borderline malignant. Thus, concluded that preparative diagnostic approach to a patient with ovarian mass includes careful history taking thorough clinical examination, ultrasound and tumour marker assays in selected cases. Conservative surgery should be the goal to preserve fertility in young patients with ovarian tumours. ${ }^{1}$ Mohapatro et al conducted a study on clinipathological spectrum of ovarian tumours in a tertiary care center. In the study 96 patients had been studied. Out of them 59 (61.45\%) cases were benign and $32(33.33 \%)$ cases. Thus, they concluded that early diagnosis and prompt treatment can definitely reduce the mortality from ovarian tumour. ${ }^{2}$

\section{METHODS}

Prospective hospital based study was done on all the women who presented with lump and/or pain or menstrual problem attending Gynecology, Surgery and oncology OPD of Geetanjali Hospital, GMCH, Udaipur.

\section{Inclusion criteria}

All the patient of ovarian tumor attending gynecology, oncology and surgery Department at GMCH having age $>18$, patients who have signed written consent and patients who will undergo USG, tumour marker, HPR and other investigations like MRI, CT etc. were included in the study.

\section{Exclusion criteria}

Any pelvic masse other than ovarian tumour, and pregnant women were excluded from the study.

\section{Method}

Examination was performed including general physical examination, detailed systemic examination and detailed gynecological examination including per abdomen, per speculum and bimanual per vaginum examination was performed and provisional diagnosis was made. Routine investigation including $\mathrm{CBC}, \mathrm{BT}, \mathrm{CT}, \mathrm{PT} / \mathrm{INR}$, blood group, TSH, blood sugar level, serum creatinine, urine complete was done. Tumour markers including CA-125,
CEA was done and LDH, AFP, LFT was performed according to case. Ultrasound examination by transabdominal or transvaginal method was done. In sonography site, size, laterality of tumour noted, consistency of mass (cytic, solid, mixed echogenic) locularity, hemorrhage, presence of ascites and evidence of metastasis were noted. In all cases we have decided the surgery first as all tumour cases were not in advance stage. Final diagnosis was confirmed by histopathological report. In the last diagnosis by clinical examination by investigations, surgery and histopathological report were correlated.

\section{Statistical analysis}

The statistical analysis was performed using IBM statistical for social sciences (SPSS).

\section{RESULTS}

In our study P/A examination 59 patients' mass was palpable, 98 cases mass was mobile, 09 also had ascites. IN P/V examination $44.66 \%$ complete mass was palpable while $55.33 \%$ only lower pole of mass palpable. $43.68 \%$ mass was mobile. Uterus was $85.43 \%$ normal in size and $14.56 \%$ atrophic size. Table 1 showing distribution to tumours according to consistency (by USG) and relation with Malignancy. $70.87 \%$ were cystic, $14.56 \%$ were solid and 14.56 were mixed type of tumours. Among there $85.43 \%$ were benign, $1.94 \%$ were borderline and $12.62 \%$ were malignant. There is significant association between USG finding and consistency of tumour.

Table 2 showing distribution according to surgery. Maximum number (43.68\%) patients had TAH with BSO, $20.38 \%$ had unilateral cystectomy, $14.56 \%$ had TAH with BSO and chemotherapy, $0.97 \%$ had debulking and $1.94 \%$ had BSO after in past hysterectomy. There is significant association between USG finding and surgery. Table 3 showing distribution according to various histological types of tumour and distribution of malignancy in them. Maximum number of patients $85.43 \%$ were benign epithelial tumour mainly serous cystic $61.16 \%, 22.33 \%$ were mucinous tumour, $8.73 \%$ were epithelial tumour have malignant $5.82 \%$ were germ cell tumour $85.43 \%$ were have benign and $12.62 \%$ were malignant. Maximum number of malignancy $8.73 \%$ were in the epithelial tumour. Rest $3.88 \%$ were in clear cell carcinoma, pseudomyxoma peritoni and metastatic carcinoma. There is significant association between USG findings and history of tumour.

Table 1: Distribution of tumours according to consistency (by USG) and relation with malignancy.

\begin{tabular}{|c|c|c|c|c|c|c|}
\hline Consistency of Tumors & Benign & Borderline & Malignant & Total & Chi-square value & P value \\
\hline Cystic & $72(81.8)$ & 0 & $1(7.69)$ & $73(70.87)$ & \multirow{4}{*}{43.66} & \multirow{4}{*}{$<0.001$} \\
\hline Mix & $6(6.82)$ & $2(100)$ & $7(53.84)$ & $15(14.56)$ & & \\
\hline Solid & $10(11.36)$ & 0 & $5(38.46)$ & $15(14.56)$ & & \\
\hline Total & 88 & 2 & 13 & 103 & & \\
\hline
\end{tabular}


Table 2: Distribution according to surgery.

\begin{tabular}{|c|c|c|c|c|c|c|}
\hline Surgery & Benign & Borderline & Malignant & Total & $\begin{array}{l}\text { Chi-square } \\
\text { value }\end{array}$ & $P$ value \\
\hline BSO (past hysterectomy) & $1(1.13)$ & 0 & $1(7.69)$ & $2(1.94 \%)$ & \multirow{8}{*}{45.47} & \multirow{8}{*}{$<0.001$} \\
\hline Unilateral slpingoophorectomy & $14(15.90)$ & $1(50)$ & 0 & $15(14.56 \%)$ & & \\
\hline Unilateral Cystectomy & $21(23.86)$ & 0 & 0 & $21(20.38 \%)$ & & \\
\hline Debulking & 0 & 0 & $1(7.69)$ & $1(0.97 \%)$ & & \\
\hline TAH+USO & $4(4.54)$ & 0 & 0 & $4(3.88)$ & & \\
\hline TAH+BSO+ICO & $6(6.81)$ & $1(50)$ & $8(61.53)$ & $15(14.56)$ & & \\
\hline TAH+BSO & $42(47.72)$ & 0 & $3(23.07)$ & $45(43.68)$ & & \\
\hline Total & 88 & 2 & 13 & 103 & & \\
\hline
\end{tabular}

Table 3: Distribution according to various histological types of tumour and distribution of malignancy in them.

\begin{tabular}{|c|c|c|c|c|c|c|c|}
\hline \multicolumn{2}{|l|}{ History } & Benign & Borderline & Malignant & Total & $\begin{array}{l}\text { Chi-square } \\
\text { value }\end{array}$ & P value \\
\hline \multirow{3}{*}{$\begin{array}{l}\text { Epithelial } \\
\text { Tumour }\end{array}$} & Endometriotic & $2(2.27)$ & 0 & 0 & $2(1.94 \%)$ & \multirow{10}{*}{31.23} & \multirow{10}{*}{$<0.013$} \\
\hline & Mucinous & $19(21.59)$ & $1(50)$ & $3(23.07)$ & $23(22.33)$ & & \\
\hline & Serous & $56(63.63)$ & $1(50)$ & $6(46.15)$ & $63(61.16)$ & & \\
\hline \multirow{2}{*}{\multicolumn{2}{|c|}{$\begin{array}{l}\text { Combined } \\
\text { Germ cell tumour }\end{array}$}} & $3(3.40)$ & 0 & 0 & $3(2.91)$ & & \\
\hline & & $6(6.81)$ & 0 & 0 & $6(5.82)$ & & \\
\hline \multicolumn{2}{|c|}{ Pseudomyxoma Peritonei } & 0 & 0 & $1(7.69)$ & $1(0.97)$ & & \\
\hline \multicolumn{2}{|c|}{ Sex cord Stroma Tumour } & $2(2.27)$ & 0 & 0 & $2(1.94)$ & & \\
\hline \multicolumn{2}{|c|}{ Clear cell carcinoma } & 0 & 0 & $1(7.69)$ & $1(0.97)$ & & \\
\hline \multicolumn{2}{|c|}{ Metastatic carcinoma } & 0 & 0 & $2(15.38)$ & $2(1.94)$ & & \\
\hline \multicolumn{2}{|l|}{ Total } & 88 & 2 & 13 & 103 & & \\
\hline
\end{tabular}

Table 4: Correlation of diagnosis of malignancy by ultrasonography and histopathology report $(\mathrm{N}=103)$.

\begin{tabular}{|lll|}
\hline USG as a screening & True & False \\
\hline Positive & 88 & 4 \\
\hline Negative & 11 & 0 \\
\hline
\end{tabular}

Table 4 showing correlation of diagnosis of malignancy by ultrasonography and histopathology report. by ultrasonography. Sensitivity (100\%), specificity (73.3\%) positive predictive value $(95.56 \%)$ and negative predictive value $(100 \%)$.

\section{DISCUSSION}

\section{Distribution according to the consistency of tumour and USG finding}

In the present study consistency was checked using USG. In benign tumour most of the patients $70.87 \%$ patients had cystic consistency of tumour. Similarly, in malignant tumours cases, most of the tumor was cystic inconsistency. Rest of the tumours were solid (11.36\% in benign and $38.46 \%$ in the malignant tumour) or mixed type $(6.82 \%$ in benign and $53.84 \%$ in malignant tumours) consistency. In the study by Kanthikar et al in the benign tumour $66.7 \%$ was cystic $13.3 \%$ was solid while $28.8 \%$ were mixed variety. Whereas in malignant tumours there was no cystic tumor, $42.8 \%$ was solid and
$55 \%$ were mixed variety whereas in the study by Phukan et al, in benign tumor $82.2 \%$ was cystic and $17.8 \%$ were mixed variety while in malignant tumour $63.6 \%$ was solid $27.3 \%$ were mixed and $9.1 \%$ work cystic.,4 According the above finding commonest consistency was in cystic in benign tumour while in malignant tumours $53.84 \%$ were mix and $38.46 \%$ was solid which is little variable to others.

\section{Distribution to various histological types of tumor and distribution of malignancy in them}

In benign tumour $(85.43 \%)$ most common variety was serous $(63.6 \%)$ followed by the mucinous tumour $(21.6 \%)$ which are epithelial tumour similar in malignant tumour $(12.62 \%)$ most common variety in serous $(46.2 \%)$ followed by mucinous $(23.1 \%)$ similarly in the study by Prakash et al serous cystadenomas were the most common lesion diagnosed (80 out of $124: 64.5 \%$ of benign neoplasia, $62.5 \%$ of all neoplastic lesions). Mucinous cyst adenomas were the second most common benign neoplastic lesion diagnosed $(30$ out of $124: 24.2 \%){ }^{5}$ Similarly in the study Deeba et al in malignant tumour most common type was serous cyst Aden carcinoma $(57.1 \%)$ followed by mucinous cyst adenocarcinoma $(21.4 \%){ }^{5,6}$ In the study by Yogambal et al benign ovarian tumours showed that the commonest tumor was serous cystadenoma $(21.4 \%)$ followed by mature cystic teratoma $(19.9 \%)$ common malignant ovarian tumors were serous cystadenocarcinoma $(9.5 \%)$ 
and mucinous cystadenocarcinoma $(3.2 \%){ }^{7}$ From above observations suggest the most common variety of in benign and malignant tumor of the ovary is epithelial tumor and commonest serous cystadenoma followed by mucinous cystadenoma.

\section{Correlation of diagnosis of malignancy by ultrasonography and histopathology report}

There was a strong correlation between diagnosis of the ovarian tumors and the ultrasonography. By ultrasonography, sensitivity was $100 \%$, specificity was $73.3 \%$ positive predictive value was $95.56 \%$ and negative predictive value was $100 \%$.

\section{CONCLUSION}

Finally, the conclusion of our study is that $85.43 \%$ were benign tumor and $12.67 \%$ were malignant tumor. Among this, $70.87 \%$ were cystic, $14.56 \%$ were solid and $14.56 \%$ were mixed tumors. Mostly they were epithelial tumors $(85.43 \%)$. Main surgery was total hysterectomy with bilateral salpingoopherectomy. In malignant tumours $61.53 \%$ also had chemotherapy and $0.97 \%$ had debulking.

Diagnosis of ovarian tumor and malignancy in ovarian tumor was diagnosed clinically and finally by Ultrasonography except $3.88 \%$ malignancy was diagnosed by frozen section or by histopathology report. There is strong correlation of ultrasonography finding and histopathology report. Specificity of the Ultrasonography was $73.33 \%$ but sensitivity was $100 \%$. Positive predictive value was $95.65 \%$ and negative predictive value was $100 \%$.

\section{Limitation}

MRI and CT scan was not done in all patients due to low socioeconomic status.
Funding: No funding sources Conflict of interest: None declared

Ethical approval: The study was approved by the Institutional Ethics Committee

\section{REFERENCES}

1. Fonseea M. A clinic-histopathological review of ovarian masses at a teriary care centre. Int J Reprod Contracept Obstet Gynecol. 2018;7(10):4139-44.

2. Mohapatro M, Dash D, Rao ES. A study on clinicopathological spectrum of ovarian tumours in tertiary care centre. J Evid Med Healthcare. 2017;4(37):2223-30.

3. Kanthikar SN. Clinico-histopathological analysis of neoplastic and non-neoplastic lesions of the ovary: a 3 year prospective study in Dhule, North Maharasthara. India J Clin Diag Res. 2014;8(8):4-7.

4. Phukan JP. Clinicopathological analysis of ovarian tumours in perimenopasusal women: a study in a rural teaching hospital of eastern India. Bangladesh J Med Sci. 2013;12(3):263-8.

5. Prakash A, Chinthakindi S. Histopathological study of ovarian lesions in a tertiary care center in Hyderabad, India: A retrospective five year study. India J Clin Diag Res. 2017;4(3):745-9.

6. Deeba F. Clinicopathological study of ovarian cancer: a multi centered study. J Shasheed Suhrawardy Med Coll. 2013;3(1):3-5.

7. Yogambal M, Arunalatha P. Ovarian tumoursincidence and distribution in a tertiary referral center in south India. IOSR J Dental Med Sci. 2016;13(3);74-80.

Cite this article as: Jain R, Patel P, Goyal S.

Clinico-pathological study of ovarian tumors at tertiary care hospital, Udaipur. Int J Reprod Contracept Obstet Gynecol 2021;10:555-8. 